\title{
VELAR VOCALIZATION OR DELETION?
}

\author{
KUNIO NISHIYAMA \\ Ibaraki University*
}

Keywords: deletion, vocalization, diachronic, synchronic, morphology

\section{Introduction}

This paper is concerned with the following paradigm with velar final verbs in Japanese:

(1) $/$ kak-te $/ \rightarrow$ kaite 'write.gerundive' /tok-te/ $\rightarrow$ toite 'solve.gerundive'

Other suffixes that show a similar paradigm are -ta 'past,' -tara 'conditional,' -tari 'and so on.' One way to account for (1) is the following:

(2) Velar Vocalization (VV)

The root-final velar is vocalized into [i].

Another way is:

(3) Velar Deletion (VD)

The root-final velar is deleted, and [i] is the result of epenthesis.

[i]-epenthesis is independently motivated with [s]-final verbs:

(4) / kas-te/ $\rightarrow$ kasite 'lend.gerundive' /otos-te/ $\rightarrow$ otosite 'drop.gerundive'

Velar Vocalization (VV) has been entertained by Itô and Mester (1986), and Velar Deletion (VD) by Davis and Tsujimura (1991), among others. Recently, Suzuki (1994) has argued for VV, claiming that VD leaves unexplained why a velar deletes. This paper defends VD, arguing that VD as a diachronic fact can be extended as a synchronic process.

* I have benefited from the discussion with Masao Okazaki, Kan Sasaki, Naoaki Wada and the two reviewers. 


\section{Velar Deletion as a Diachronic Process}

I would like to note first that VD is attested widely in the history of Japanese in independent contexts as one instantiation of the so-called $i$ onbin, as follows:

( 5 ) tuitati 'the first day of the month'<tuki 'moon'+tati 'stand' VD is also attested in attributive adjectives:

(6) aoki umi > aoi umi 'blue sea'

This is exactly parallel to the following historical change of the gerundive form of velar-final verbs:

(7) kakite > kaite 'write.gerundive'

Note the parallelism between tuki > tui (5), aoki > aoi (6), and kakite $>$ kaite (7). Since the only difference is that the velar segment $[\mathrm{k}]$ is missing in the modern form, one cannot deny the existence of VD as a diachronic process. Of course, it is one thing to say that there is a diachronic process, and it is another to say that the same process exists synchronically. In the next section, I argue that VD is motivated in Modern Japanese as well.

\section{Velar Deletion as a Synchronic Process}

We have seen in the previous section that adjectives attest VD diachronically. Adjectives also provide what may constitute evidence for VD in Modern Japanese. Suppose that adjective roots in Modern Japanese are uniformly [k]-final (cf. Urushibara (1993: 49) and Miyagawa (1998: 437)). Then the modern form [ao-i] in (6) is underlyingly /aok-i/ and the surface form is obtained by VD. One attractive aspect of this analysis is that it explains why adjectives always involve [k] in non-present forms:

( 8 ) aokatta (Past), aokereba (Cond), aokaroo (Presumptive), aokute (Gerund)

If, as standardly held, $[\mathrm{k}]$ is a part of the suffix, a question arises why all the suffixes that follow adjectives are [k]-initial. If $[\mathrm{k}]$ is a part of the root, no such question arises. In this analysis, examples in (8) are segmented as aok-atta, aok-ereba, aok-aroo, and aok-u-te. ${ }^{1}$ Similarly,

1 Another possibility is that $/ \mathrm{k} /$ is an independent inflectional affix that follows an adjectival root. 
the present form is underlyingly /aok-i/, and the surface form is obtained by VD. If this analysis is correct, VD is motivated in Modern Japanese, justifying extension of the diachronic process in (7) to Modern Japanese as a synchronic process.

\section{Velar Deletion as a Morphological Process}

As noted in section 1, the alleged disadvantage of VD is that it does not explain why velars delete. In this section, I argue that this is not a problem, because the process in question is not phonological but morphological.

Let us first review Suzuki's (1994) argument for VV. The following is a part of the paradigm of the gerundive -te which is relevant in the following discussion:

(9) a. [r]-final verbs $/$ kar-te $/ \rightarrow$ katte 'trim.gerundive'

b. [s]-final verbs /kas-te/ $\rightarrow$ kasite 'lend.gerundive'

c. velar-final verbs /kak-te/ $\rightarrow$ kaite 'write.gerundive'

Note that [r]-final verbs induce gemination (9a) and [s]-final verbs induce epenthesis $(9 b)$, and I will not discuss here why [r]-final verbs and [s]-final verbs behave differently, concentrating on why velar-final verbs behave as in (9c). See Davis and Tsujimura (1991) and references cited therein for an account of $(9 a, b)$. Suzuki (1994) argues that one factor that triggers $\mathrm{VV}$ is the Obligatory Contour Principle (OCP). Abstracting away from the technical details, what differentiates $(9 c)$ from $(9 a, b)$ is that in $(9 c)$, there is a consonant cluster that consists of a sequence of two stops (i.e. $/ \mathrm{k}-\mathrm{t} /$ ) with the $[-$ cont $]$ feature. The consonant clusters in $(9 \mathrm{a}, \mathrm{b})(\mathrm{i} . \mathrm{e} . / \mathrm{r}-\mathrm{t} / \mathrm{and} / \mathrm{s}-\mathrm{t} /)$, on the other hand, contain only one stop. Thus, only (9c) violates the OCP, and this eventually leads to vocalization of the velar. See Suzuki (1994: 240) for the formal process of VV.

To the extent that Suzuki resorts to the general principle of the OCP, he is assuming that the process in question is phonological. But consider the following:

(10) a. /kak-tai/ $\rightarrow$ kakitai 'write.want'

b. /kak-tasu/ $\rightarrow$ kakitasu 'write-add'

Unlike the gerundive form in $(9 c)$, the desiderative form (10a) and a verbal compound (10b) induce epenthesis. Since there is no difference at the morpheme boundary in the underlying form between / kak-te/, 
/ kak-tai/, 2 and/ kak-tasu/, the VV account must make the stipulation that the OCP applies only in the presence of -te (and other -ta-initial suffixes). This is an undesirable consequence, since the OCP is a general phonological principle and is unlikely to be sensitive to morphological contexts. ${ }^{3}$ In other words, even if one tries to account for the process in question in phonological terms, there is no way to avoid mentioning morphological contexts. Thus, it seems to be more desirable to try to account for the process in question in morphological terms from the beginning, namely in terms of VD. Although the present analysis does not explain why velars delete, we saw in section 2 that VD is a historical fact in Japanese, whatever the reason is. Thus, it is not a burden for the VD analysis of velar-final verbs to explain why velars delete. Instead, the burden for the present analysis is to justify extending this historical fact to the synchronic paradigm, which I did in section 3. As long as the alleged disadvantage of VD can be eliminated, VD seems to be more desirable.

The contexts for VD in Modern Japanese are summarized as follows: ${ }^{4}$

2 Davis and Tsujimura (1991: 141) assumes that the desiderative suffix is underlyingly /itai/. If this were the case, [kakitai] would cease to be a problem for the OCP, because it is underlyingly / kak-itai/ and there is no (stop-only) consonant cluster. However, this construal cannot be extended to verbal compounds as in (10b), because the underlying form of 'add' cannot be /itasu/.

3 Although phonological principles are sometimes claimed to be sensitive to morphological contexts (Prince and Smolensky (1993: 101), due to a reviewer), such a situation is better avoided.

4 Thanks to a reviewer for pointing out the relevance of making the contexts explicit. The contexts in (11) are not satisfied in the following:

(i) okite 'wake.gerundive' kaki 'oyster'

(ii) aokute 'blue.gerundive'

In (i), the / $i$ / is not epenthetic but a part of the root, and in (ii), the relevant vowel is not even $/ \mathrm{i} /$. The contexts in (11) can be extended to the VD as a diachronic process for the most part, except for (5), as pointed out by the reviewer.

The same reviewer asks how the present analysis treats the following:

(iii) $/$ tog-te $/ \rightarrow$ toide 'sharpen.gerundive'

This can be accounted for by assuming that VD follows Voice Spread (in derivational terms) or that even after the deletion (unparsing), the [+voice] feature of the root-final segment is parsed and linked to the suffix-initial consonant (in representational terms). 
(11) a. Before an epenthetic [i] followed by -te, -ta, -tara, and -tari

b. Before the (adjectival) present marker /i/

Although (11a) and (11b) do not form a natural class, this is fine, since VD is a synchronic morphological process in the present analysis, closely related to the same process as a historical change. Since VD as a diachronic process is sensitive to morphological contexts, as we saw in section 2, the contexts for VD as a synchronic process in (11) are also morpheme-specific. To be more precise, VD might be a case of Readjustment in the sense of Chomsky and Halle (1968: 9ff) and Halle and Marantz (1993: 124ff).

\section{Conclusion}

In this paper I have argued that, despite the recent trend for $\mathrm{VV}$, the VD analysis for [kaite] has a natural source in its diachronic status, and that its scope can be extended to synchronic paradigm as a morphological process. Although it is a Saussurean maxim that one can do synchronic research without considering diachronic facts, this paper argued that when synchronic data allow two competing analyses, diachronic facts provide decisive arguments. ${ }^{5}$

\section{REFERENCES}

Chomsky, Noam and Morris Halle (1968) The Sound Pattern of English, Harper and Row, New York. [Reprinted by MIT Press, Cambridge, MA, 1991.]

Davis, Stuart and Natsuko Tsujimura (1991) "An Autosegmental Account of Japanese Verbal Conjugation," Journal of Japanese Linguistics 13, 117144.

Halle, Morris and Alec Marantz (1993) "Distributed Morphology and the Pieces of Inflection," The View from Building 20, ed. by Kenneth Hale and Samual Jay Keyser, 111-176, MIT Press, Cambridge, MA.

5 As pointed out by a reviewer, the same spirit is shared by Chomsky and Halle (1968: chapter 6) and a series of works by Paul Kiparsky in the late 1960s and the early $1970 \mathrm{~s}$. 
Itô, Junko and Armin R. Mester (1986) "The Phonology of Voicing in Japanese: Theoretical Consequences for Morphological Accessibility," Linguistic Inquiry 17, 49-73.

Miyagawa, Keiko (1998) "The Japanese Dummy Verbs and the Organization of Grammar," Japanese/Korean Linguistics 7, 427-443, CSLI Publications, Stanford.

Prince, Alan and Paul Smolensky (1993) "Optimality Theory," ms., Rutgers University and University of Colorado.

Suzuki, Takeru (1994) "Explaining Velar Vocalization," English Linguistics 11, 237-244.

Urushibara, Saeko (1993) Syntactic Categories and Extended Projections in Japanese, Doctoral dissertation, Brandeis University.

Faculty of Humanities

Ibaraki University

Bunkyo, Mito

310-8512

e-mail:kn20@mito.ipc.ibaraki.ac.jp 